\title{
Circadian blood variations and performance effects in dairy cows fed during the day or the night
}

\author{
G. Bertoni' ${ }^{1}$, R. Lombardelli and E. Trevisi \\ Istituto di Zootecnica, Facoltà di Agraria, Università Cattolica del Sacro Cuore \\ Via Emilia Parmense, 84 - 29100 Piacenza, Italy
}

\begin{abstract}
Effects of feeding pattern (day or night meals) on circadian blood changes and milk composition were studied in 4 dairy cows in a double Latin square design. Night meals reduced the speed of feed intake, inducing important endocrine-metabolic changes and reduced differences between fat and protein percentage of 2 consecutive milkings. The results have practical implications at the farm level and for blood analysis interpretation.
\end{abstract}

KEY WORDS: feed intake, circadian pattern, metabolic profile, dairy cows

\section{INTRODUCTION}

Important blood changes of metabolites and hormones occur during the day in the dairy cow. Several causes (i.e. feeding frequency and its pattern, lactation stage, light/dark cycle) can explain these variations (Bertoni et al., 1993). These daily fluctuations of blood parameters could affect milk performances and feed efficiency as well as the metabolic profile interpretation (Bertoni et al., 1993). The aim of the present study was an attempt to evaluate the effects of feeding pattern (day or night period).

\section{MATERIAL AND METHODS}

Four Italian-Friesian dairy cows in their late lactation housed in tie-stalls under artificially ventilated and lighted (from 6.00 to 20.00) conditions were used.

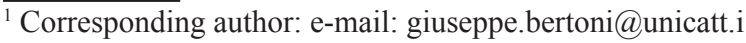


Cows were individually fed with 2 equal meals of forages and 7 equal meals of concentrate, in average $10 \mathrm{~kg} / \mathrm{d}$ distributed by autofeeder, from $30 \mathrm{~min}$ before $1^{\text {st }}$ forage meal and 2.5, 5.0 and $7.5 \mathrm{~h}$ after both forage meals. Therefore the cows remained $8 \mathrm{~h}$ without any new feed distribution. The meals, according to a double Latin square design, were provided at 8-16 h intervals during diurnal (DM; 7.30 and 15.30) or nocturnal hours (NM; 19.30 and 3.30), for a 2-week period. Feed intake and milk yield (6:00 and 16:00) were daily recorded. Representative milk samples from both milkings were taken every 3-4 days for lactose, fat and protein determination. Jugular blood samples, in Li-heparin tubes, were drawn every 3-4 days at 7.00 a.m. and, during the last day of the trial, at $-0.5,+0.5,2,3.5,5.5$, $7.5,9.5,11.5,12.5,14,15.5,17.5,19.5,21.5$ and $23.5 \mathrm{~h}$ from $1^{\text {st }}$ forage meal. On plasma stored at $-20^{\circ} \mathrm{C}$, metabolic profile as well as insulin were analysed according to Bertoni et al. (1993).

Data were processed according to a repeated-measures MIXED procedure of SAS and the model included treatment, time and their interaction.

\section{RESULTS}

The main results will be presented in relation to feed intake behaviour, milk yield and composition, major blood parameter changes. The total dry matter intake was similar (22.7-22.8 kg/d), but forage consumption was quicker in the DM cows, in contrast it was particularly slow after $2^{\text {nd }}$ meal of NM (03.30), with a recovery later in the morning. Milk yield (Figure 1) was significantly higher (20.4 vs 19.3 $\mathrm{kg} / \mathrm{d}$ ) with a higher persistency ( 97 vs $93 \%$ of the starting yield-; $\mathrm{P}<0.05$ ) in the NM cows. The somatic cell counts did not change, otherwise the fat and protein contents were affected to some extent; namely that the fat content of morning and afternoon milkings had an opposite pattern of change as a consequence of diurnal or nocturnal meals. Thus, at the a.m. milking, the fat content increased when cows were switched to NM and decreased when they returned to DM. Because the opposite did occur at the p.m. milking, the milk fat content of the two daily milkings was very similar at the end of the experimental periods for NM and quite different for DM cows: i.e. 4.04 in the afternoon and $3.39 \%$ in the morning $(\mathrm{P}<0.001)$.

The circadian blood variations were also different in DM and NM; in fact the after meal reduction of NEFA was only observed after $1^{\text {st }}$ meal of DM cows (from 0.035 to $0.012 \mathrm{mmol} / \mathrm{l}$ ). Furthermore, urea was reduced (after a short raise; Figure 2 ) as a consequence of $1^{\text {st }}$ meal in both groups, while the changes after the $2^{\text {nd }}$ one were opposite: i.e. increased in the NM and again slightly reduced in the DM cows ( $\mathrm{P}<0.05$ between the two groups, only in this period). The changes of insulin (Figure 2) were also similar after $1^{\text {st }}$ meal (slight increase), but different $(\mathrm{P}<0.05)$ after the $2^{\text {nd }}$ one: i.e. big increase in the DM and very slight increase in NM cows. 
Moreover it was observed that insulin was very stable during the $24 \mathrm{~h}$ in the NM cows; while it was very changeable in the DM cows (from the lowest, morning, to the highest, late afternoon, values: 11-24 $\mu \mathrm{UI} / \mathrm{ml}$ ).
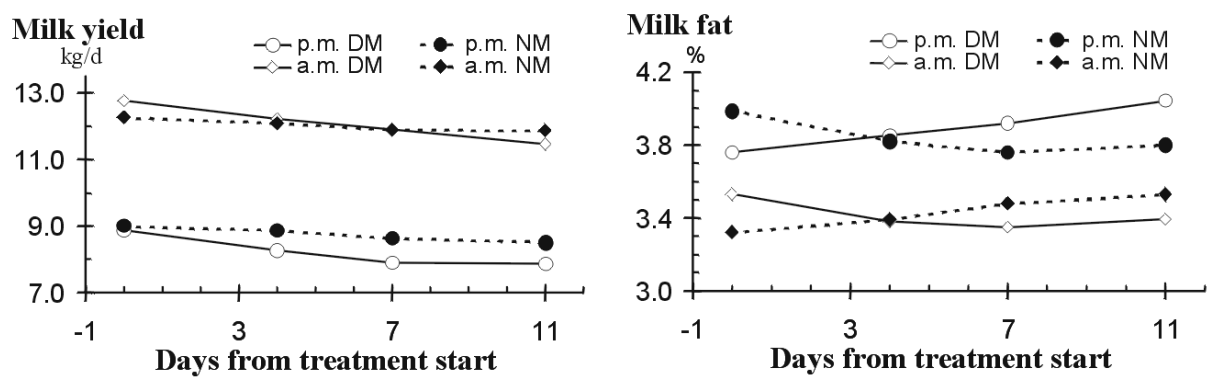

Figure 1. Milk yield and milk fat content of morning (a.m.) and afternoon (p.m.) milkings in diurnal(DM) and nocturnal-fed (NM) cows during the trial
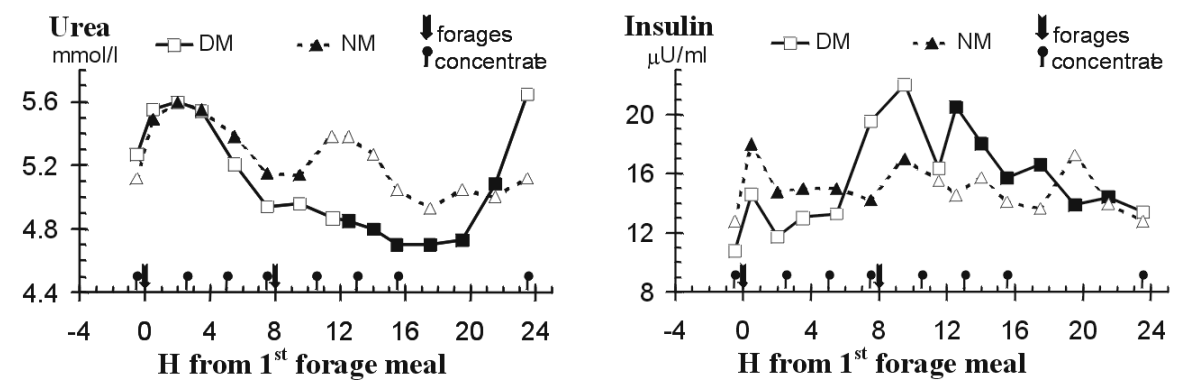

Figure 2. Twenty-four-hour patterns of urea and insulin in diurnal- (DM) and nocturnal-fed (NM) cows; mean plasma concentrations are plotted as a function of time after $1^{\text {st }}$ forage meal (7.30 for DM and 19.30 for NM; empty/full markers are for light/dark hours)

\section{DISCUSSION}

A different pattern of diet administration can modify the feed intake of dairy cows, namely that they are more active during the day and that the intake can be almost complete during daytime, if the meals are diurnal.

On the contrary, nocturnal meals tend to induce a higher intake during the night, but a large proportion of it remains for the following daytime. This has of course an effect on the size, number and time covered by real meals, therefore, nutrient absorption pattern would be modified thus justifying different levels of some hormones and particularly of insulin. In fact our results, with a lower variation of insulin in the NM cows (better spread-over-24 h feed intake), agree quite well with Dawson (1999) that suggests: well-distributed meals maintain a 
"constant" concentration of insulin. In agreement with these hormonal changes are those of NEFA and urea; these metabolites are in fact increased when a lower gut absorption of nutrients requires body tissue mobilization: therefore lipolysis and protein degradation will allow for a higher catabolism and urea synthesis. In fact, a similar situation: high and "continuous" gut absorption during the day and low gut availability during the night, would only occur in DM cows. According to a previous paper (Bertoni et al., 1993) and confirmed herein, the consequences are quite low values of insulin in the early morning and quite high in the evening; this finding contributes to understand the opposite changes of NEFA and urea (high in the morning and low in the afternoon). The reverse is obviously true for NM cows and, as previously suggested by Dawson (1999) a better uniformity of $24 \mathrm{~h}$ intake could allow a higher protein synthesis efficiency. This could, in turn, justify the better persistency of milk yield observed in the NM cows characterized, in fact, by a more uniform daily feed intake. However, some positive effects could also be ascribed to a better rumen activity (Robinson, 1989). At the end, it seems noteworthy that the mammary fat synthesis could be affected by the blood insulin changes, namely the milk fat content of DM cows is lower in the morning (milking occurring after an interval with very high insulin at the beginning), otherwise it is higher in the afternoon (milking after an interval starting with a low insulin level that have induced an increase of tissue lipolysis and protein breakdown).

\section{CONCLUSIONS}

The feeding pattern of dairy cows can be modified, to some extent, resulting in endocrine and metabolic changes, which seem also to affect milk yield and composition. This could be of practical interest at the farm level, and it should be considered when blood analysis (i.e. bleeding time and their interpretation) have to be performed.

\section{REFERENCES}

Lombardelli R., Bertoni G., Piccioli Cappelli F., 1993. Frequenza dei pasti nelle bovine da latte: effetti a livello metabolico, endocrino e produttivo. Zoot. Nutr. Anim. 19, 123-130

Dawson J.M., 1999. Variation in nutrient supply and effects on whole body anabolism. In: Proceedings of VIIIth Protein Metabolism and Nutrition Sympsium. EAAP Publication No. 96, Wageningen Pers, pp. 101-126

Robinson P.H., 1989. Dynamic aspects of feeding management for dairy cows. J. Dairy Sci. 72, 1197-1209 